\title{
IMPLICAÇÕES DA INCLUSÃO NO PROCESSO PEDAGÓGICO*
}

Luciana Pacheco Marques**

\section{RESUMO}

A apreensão dos sentidos dados na atualidade à problemática vivida pelos sujeitos evidencia três diferentes concepções nos discursos da escola sobre diversidade, três formações ideológicas que bem caracterizam as atitudes humanas diante da diferença: a da exclusão, a da integração e a da inclusão, identificados, respectivamente, como os paradigmas do isolamento, da visibilidade e da acessibilidade, sendo que cada uma delas implica em um olhar sobre o processo pedagógico. Temos, pois, a coexistência de três formações discursivas no processo pedagógico: a educação que "nega" a existência do outro; a que abriga e "enforma" o outro; e a que vive a "complexidade" do/no cotidiano em sua diversidade e riqueza.

Palavras-chave: educação; diferença; inclusão; processo pedagógico.

A diversidade humana é inegável. Mas a escola, apesar de ser um espaço onde as diferenças coexistem, nem sempre reconheceu sua existência ou considerou-a na sua complexidade, em todos os elementos do processo pedagógico.

Esses elementos se constituem nos objetivos, conteúdos, metodologias e recursos, relação professor-aluno e avaliação. Os objetivos educacionais antecipam resultados e processos esperados do trabalho conjunto do professor e dos alunos. Os conteúdos de ensino constituem o conjunto de conhecimentos, habilidades, hábitos, modos valorativos e atitudinais. As metodologias e os recursos de ensino são meios para se

* Artigo recebido em 21/7/2006 e aprovado em 18/9/2006.

** Doutora em Educação pela Unicamp e professora da Universidade Federal de Juiz de Fora. E-mail: Luciana.marques@ufjf.edu.br 
alcançar os objetivos gerais e específicos da educação. A relação professor-aluno envolve tanto o aspecto cognoscitivo, que diz respeito às formas de comunicação dos conteúdos escolares e às tarefas escolares, quanto o aspecto socioemocional, que diz respeito às relações pessoais entre professor e aluno e às normas disciplinares. A avaliação escolar consiste no acompanhamento do processo educacional, envolvendo os aspectos quantitativos e qualitativos.

Constata-se a existência de três diferentes concepções nos discursos da escola sobre a diversidade, três formações ideológicas que bem caracterizam as atitudes humanas diante da diferença: a da exclusão, a da integração e a da inclusão, identificadas, respectivamente, como os paradigmas do isolamento, da visibilidade e da acessibilidade (MARQUES, 2001), sendo que cada uma delas implica em um olhar sobre o processo pedagógico.

Durante muito tempo negou-se a existência do diferente no processo pedagógico. Constituiu-se, assim, uma prática pedagógica de isolamento, configurando a formação ideológica da exclusão.

A diferença era percebida como "desvio", tendo como referencial a dicotomia normalidade $\mathrm{X}$ anormalidade, demarcando a existência de fronteiras entre aqueles que se encontravam dentro da média e os que estavam fora desta.

Na exclusão não paira, pois, qualquer dúvida sobre o seu caráter unilateral do isolamento, em uma prática verticalizada, de cima para baixo, do dominante em relação ao objeto de dominação, o desviante.

Identificada como uma das mais importantes marcas do pensamento moderno, a caracterização da diferença como anormalidade representa uma primeira formação discursiva, a qual traz implícito o referencial de normalidade como parâmetro para tal caracterização. O que está em jogo é, na verdade, a apologia do normal. A anormalidade não passa, pois, do contraponto necessário para a construção do sentido de normalidade. Vaz (s.n.t.) identifica esse mecanismo como um procedimento típico do pensamento moderno, cuja prática social encontrase fundada na normatização e no controle disciplinar.

Os diferentes foram, assim, historicamente discriminados. Vítimas da rejeição e/ou da compaixão social, estiveram sempre à margem do convívio com os cidadãos considerados normais, sendo, inclusive, segregados, em muitos dos casos, em ambientes (instituições) restritivos, como 
são os casos dos asilos, das escolas especiais, dos hospitais psiquiátricos etc.

Cabia à escola classificar e selecionar os sujeitos, isolando os que fugiam ao padrão construído socialmente.

É, de acordo com Skliar (2002), a pedagogia de sempre, que "nega" a existência do outro duas vezes, tanto por não enunciá-lo quanto por não permitir que ele mesmo se enuncie. Não há senão uma menção ouum anúncio forçado e inevitável.

No modelo tradicional de educação, de acordo com Luckesi (1983, p. 32), "na escola aprende-se o já aprendido e não propriamente o mundo. $\mathrm{O}$ mundo fica intermediado pelo livro texto; o mundo evidentemente do autor e não o mundo-realidade."

A formulação dos objetivos baseia-se na transmissão e na reprodução dos conteúdos previamente determinados, sendo o "bom aluno" aquele que mais absorve o que for ensinado.

A metodologia envolve freqüentemente aula expositiva e demonstrações do professor. O professor fala, o aluno escuta e reproduz o que lhe foi passado. O magistério passa a ser concebido como uma arte centrada no professor. Cabe ao professor manter o aluno interessado e atento. Igualam-se os alunos: todos são tratados igualmente, todos apresentam o mesmo ritmo e adquirem os mesmos conhecimentos. Quanto às disciplinas, umas são consideradas mais importantes do que outras, possuindo uma carga horária maior.

A relação professor-aluno constitui-se como uma relação autoritária, na qual o professor impõe ao aluno a sua tarefa, permanecendo heterônoma a atividade intelectual e moral do aluno.

A avaliação é empregada para medir a quantidade e exatidão de informações que se consegue reproduzir. Provas, argüições etc. têm um fim em si mesmas, mantendo um ritual eficiente e satisfatório para o modelo autoritário deste tipo de sociedade.

Observa-se, todavia, um deslocamento de sentido na direção da superação desse modelo excludente de sociedade por um novo modelo fundado no reconhecimento e no respeito à diferença. Segundo Fonseca (1995, p. 44),

Nos nossos dias o direito de ser diferente é também visto como um direito humano, que passa naturalmente pela análise crítica dos critérios sociais que impõem a reprodução e a preservação de uma 
sociedade [...] baseada na lógica da homogeneidade e em normas de rentabilidade e eficácia, que tendem facilmente a marginalizar e a segregar quem não acompanha as exigências e os ritmos sofisticados.

Neste contexto, situa-se a integração, caracterizada ideologicamente pelo confronto entre o discurso dominante da exclusão e aquele construído a partir da voz dos diferentes e/ou das pessoas com eles envolvidas na luta pelo reconhecimento da diferença como condição existencial possível.

Tal formação ideológica tem seus pilares na organização e na ascensão dos movimentos sociais, cujas vozes procuram - ou pela denúncia das práticas discriminatórias ou pela reivindicação de igualdade social dar visibilidade à diferença e ocupar os espaços deixados pela ideologia dominante, fundadora do modelo social da exclusão, o que se dá tanto em relação ao espaço físico quanto em relação ao espaço discursivo.

Todavia, a integração assumiu um sentido unilateral, ficando reduzida ao esforço individual de inserção do diferente no contexto social. O mérito pessoal constitui, pois, a chave para o sucesso. A integração consiste no fato de se inserir na sociedade os diferentes que alcançaram, por eles próprios, um nível de competência compatível com os padrões sociais vigentes.

Esse discurso meritocrático evidencia, mais uma vez, a prática social da discriminação e do preconceito, pois, ao mesmo tempo em que alguns são "aceitos", a estrutura social da segregação é mantida inabalável, e, pior, seu sentido é ainda mais reforçado pela "prova concreta" da incapacidade de inserção apresentada pelos diferentes, "fracassados" no seu empreendimento pessoal de inserção. As instituições devem ser mantidas, pois há quem necessite delas.

Esta foi outra forma como a escola se relacionou com o diferente: abrigando-o, mas "enformando-o". Constituiu-se, assim, uma prática pedagógica de visibilidade, configurando a formação ideológica da integração.

A diferença era percebida como possível, mas só se admitia a possibilidade de inserção de alguns considerados capazes.

É, segundo Skliar (2002), a pedagogia que hospeda, que abriga, mas que não se importa com quem é o seu hóspede. Representa o nosso discurso acadêmico que tenta traduzir e representar o outro, na intenção ingênua de inseri-lo, no sentido de "colocar dentro" de uma mesmidade o "outro" ainda como o diferente - e não como diverso. 
É a ambição do texto da mesmidade que tenta alcançar o outro, capturar o outro, domesticar o outro, dar-lhe voz para que diga sempre o mesmo, exigir-lhe sua inclusão, negar a própria produção de sua exclusão e de sua expulsão, nomeá-lo, confeccioná-lo, dar-lhe um currículo "colorido", oferecer-lhe um lugar vago, escolarizá-lo cada vez mais para que, cada vez mais, possa parecer-se com o mesmo, ser o mesmo. [...] Uma pedagogia que reúne, ao mesmo tempo, a hospitalidade e a hostilidade em relação ao outro. Que anuncia sua generosidade e esconde sua violência de ordem. (SKLIAR, 2002, p. 213-214)

É a pedagogia do outro como figura folclórica, como data cívica, como tema de celebração em uma semana especial. É também a pedagogia da escola que hospeda a criança considerada diferente, ainda que com boa vontade e intenção de atender às suas necessidades da melhor forma, mas ao mesmo tempo a encara como ser diferente da suposta mesmidade com a qual está habituada.

$\mathrm{Na}$ integração ainda prevalece o modelo tradicional de educação, porém se evidencia as diferenças no desenvolvimento do processo pedagógico.

A formulação dos objetivos ainda baseia-se na transmissão e na reprodução dos conteúdos previamente determinados para o "bom aluno". Porém, sabe-se da existência de um outro diferente, colocado na condição do que não sabe, do que não aprende.

A metodologia deveria envolver aulas dinâmicas que respeitassem o ritmo diferenciado dos alunos, porém ainda se mantém no modelo tradicional, ou seja, na aula expositiva e nas demonstrações do professor. O magistério passa a ser concebido como uma arte centrada no aluno. Cabe ao aluno responder ao processo de ensino em que está inserido. Diferenciam-se os alunos: cada um tem um ritmo de aprendizagem. Algumas disciplinas ainda são consideradas mais importantes do que outras, possuindo uma carga horária maior.

Procura-se quebrar a relação autoritária entre professor e aluno, na qual o professor se aproxima do aluno para compreender seu ritmo de aprendizagem, buscando-se uma autonomia na atividade intelectual e moral do aprendiz.

A avaliação é empregada para verificar o que cada um aprendeu. É o maior recurso utilizado para dizer de quem aprende ou/e de quem não aprende, quem é o "bom aluno" e quem é aquele outro que deve ficar à margem do processo educacional. 
A inclusão, por sua vez, caracteriza-se pela preocupação alimentada principalmente pela ciência e pela tecnologia em se melhorar as condições de vida de todas as pessoas, através da facilitação do acesso de todos aos recursos disponíveis, tendo como princípio o dado da diversidade como característica maior da existência humana.

Segundo Silva (2000, p. 44),

No contexto da chamada "política de identidade", o termo está associado ao movimento do multiculturalismo. Nessa perspectiva, considera-se que a sociedade contemporânea é caracterizada por sua diversidade cultural, isto é, pela coexistência de diferentes e variadas formas (étnicas, raciais, de gênero, sexuais) de manifestação da existência humana, as quais não podem ser hierarquizadas por nenhum critério absoluto ou essencial.

Ser diferente não significa mais ser o oposto do normal, mas apenas "ser diferente". Este é, com certeza, o dado inovador: o múltiplo como necessário ou, ainda, como o único universal possível.

O que se apreende desse movimento típico da atualidade é a idéia de que o mais importante na vida de qualquer pessoa é a capacidade de acessar as informações e os espaços, não se importando pela utilização de um corpo biologicamente perfeito ou pelo emprego de recursos tecnológicos que favorecem a inserção dos seus usuários nas diversas situações da vida em sociedade.

Essa formação discursiva tem como base a formação ideológica que projeta a ciência e a tecnologia como elementos determinantes da vida contemporânea, e a cuja orientação a ação humana está cada vez mais condicionada.

Isso implica em afirmar que a ciência hoje é mais do que um instrumento de leitura e descoberta do mundo; ela é, juntamente com a tecnologia, uma responsável direta pela redefinição do mundo no qual vivemos; ou seja, ela é um elemento fundador e, por isto, estratégico em todo o contexto sociopolítico, econômico e cultural dos nossos dias, aliás, o único lugar cabível para ela. Nas palavras de Nicolescu (1995, p. 11),

Em particular, nós não temos mais hoje o direito de afirmar que o único fim digno da ciência é a descoberta do mundo a partir do ponto de vista exterior ao qual só poderia ter acesso um desses demônios que povoam as exposições da ciência clássica. Veremos que nossas 
teorias mais fundamentais se definem doravante como obra de seres inscritos no mundo que eles exploram. Nesse sentido, a ciência abandonou, portanto, toda a ilusão de extraterritorialidade teórica, e as pretensões desta ordem não podem mais se autorizar a não ser de tradições e esperanças. [...] É urgente que a ciência se reconheça como parte integrante da cultura no seio da qual se desenvolve.

$\mathrm{Na}$ verdade, experimentamos a transição de um modo de se ver o homem, o mundo e a vida para um novo modo de ser. O que sabemos apenas é que a vida está mudando e que os homens precisam construir uma nova identidade, ajustada ao ritmo e à capacidade de transformação da atualidade.

O entendimento dos novos rumos que vem tomando a humanidade depende da compreensão do modo como era concebida a própria vida. $\mathrm{O}$ descortinamento do processo de transição entre o pensamento da modernidade e o da atualidade constitui, pois, condição básica para a tentativa de se responder a tantas questões que ora nos instigam e nos desafiam.

O que se pretende na atualidade é que, no processo pedagógico, viva-se a "complexidade" do/no cotidiano em sua diversidade e riqueza. O que se busca é a constituição de uma prática pedagógica da acessibilidade, dentro da formação ideológica da inclusão.

Isso implica pensar uma sociedade sem referenciais determinados, em pensar os sujeitos na sua diferença, dentro de uma formação discursiva que tenha como pressuposto o fato de que os dados constituem-se em um determinado momento, são históricos, sociais, culturais, não existindo um referencial único, mas uma disposição para lidarmos com os dados e para considerarmos todas as possibilidades da vida. Isto não constitui uma simples superação do princípio da igualdade entre os homens como valor absoluto pelo princípio de que somos todos diferentes em características e em direitos. A diversidade implica a preservação do dado de que todas as pessoas são iguais no que se refere ao valor máximo da existência: a humanidade do homem. A diferença não deve, pois, representar um critério de hierarquização da qualidade humana. Assim, o que se deve considerar no processo pedagógico é a diferença na totalidade e a totalidade na diferença, sem se prender à prejudicial polarização do normal (igual), de um lado, e do diferente (desigual), do outro. 
Entendendo a inclusão como o princípio alicerçado no dado atual da diversidade, que contempla necessariamente todas as formas possíveis da existência humana, considera-se que ser negro ou branco, ser alto ou baixo, ser deficiente ou não-deficiente, ser homem ou mulher, ser rico ou pobre são apenas algumas das inúmeras probabilidades de ser humano.

Nessa concepção, propõe-se um discurso que vá além de uma igualdade educacional, em que o sujeito seja aceito e compreendido dentro de uma pluralidade etnocultural. Para tanto, a escola deverá adotar uma prática reflexiva e culturalmente comprometida, defendendo a construção de um currículo que desafie os discursos evidenciadores dos diferentes, promovendo a compreensão da diversidade.

É, segundo Skliar (2002), a pedagogia de um outro tempo. Uma pedagogia que não pode "ordenar, nomear, definir ou fazer congruentes os silêncios, os gestos, os olhares e as palavras do outro" (p. 214). É a pedagogia que pretendemos, mas não sabemos fazer. É a pedagogia de experiências ricas de cotidianos diversos, que empobrecemos na medida em que pesquisamos e tentamos traduzir em relatórios, utilizando, para tal, referenciais do discurso proprietário ou colonizador, nos quais estamos mergulhados.

É a pedagogia que não se preocupa mais em como seria a escola "se o outro não estivesse aqui" (SKLIAR, 2002). Que não ocupa todo o seu tempo imaginando como seria... se fossem todos normais, se todos aprendessem, se todos os professores fossem bem instruídos e bem pagos, se todas as escolas fossem bem equipadas, se toda gestão fosse democrática... É a pedagogia que vive a realidade tal como ela é, em sua diversidade e riqueza.

Segundo Candau (2003), o interculturalismo "se contrapõe à guetificação e quer botar a ênfase nas relações entre diferentes grupos sociais e culturais. Quer estabelecer pontes. Não quer fechar as identidades culturais na afirmação das suas especificidades". Em linhas gerais, esta perspectiva intercultural não nega os conflitos e aposta na relação negociada entre grupos sociais e étnicos.

Skliar (2001) considera que as mudanças textuais ou legais no processo pedagógico deveriam ser pontos de chegada, partir dos anseios e entendimentos dos diretamente envolvidos no processo educacional, sejam professores, alunos, pais, sindicatos e comunidade.

O cotidiano deve ser vivo, acontecendo a aprendizagem com as práticas coletivas, com os movimentos sociais (ARROYo, 2001), enfim, na relação com o contexto em que se inserem. 
Também as transformações de código pedagógico - envolvendo currículos, programas de formação de professores, didáticas - deveriam iniciar-se nas práticas dos professores e alunos, ou seja, nas atividades daqueles que de fato concretizam a educação (SKLIAR, 2001).

Porém, é de suma importância que se parta da mudança das identidades dos professores, dos alunos e das escolas, de modo que todos os sujeitos possam assumir sua condição de agente das situações e nunca de objeto do qual se fala ou se refere; e das representações, de modo que denunciem a situação de status quo que a sociedade vive, visando questionar e problematizar os atuais discursos e as práticas hegemônicos imersos no contexto social, para que façam sentido as mudanças nos códigos pedagógicos e nos textos legalmente reconhecidos (SKLIAR, 2001).

Quanto à formação dos professores dentro de uma política de educação inclusiva, Skliar (2001) considera que todos os profissionais deveriam ser imersos ao mundo da alteridade, possibilitando, através de sua formação, uma mudança em suas representações políticas e culturais sobre os sujeitos.

O atual momento histórico exige uma participação efetiva da escola como instituição locus do conhecimento e da formação de cidadãos transformadores dos rumos da sociedade. Neste sentido, faz-se necessária uma escola criativa onde todos os seus componentes sejam co-sujeitos na produção de um saber-instrumento para o convívio escolar e social.

Cabe, portanto, a cada um de nós, sujeitos desse processo, planejar e construir as diferentes etapas de nossa caminhada: etapas que, se em um primeiro momento são idealizadas, logo transformam-se em realidade, pela reflexão crítica de nossas próprias possibilidades na construção dessa outra escola.

Para tal, é preciso redimensionar o modo de pensar e fazer a educação, tarefa por natureza complexa, que envolve elementos políticos, socioeconômicos, técnicos e culturais. Essa postura, por sua vez, implica na superação da dicotomia e fragmentação das atribuições dos agentes educativos, dos rituais, dos conteúdos metodológicos, dos recursos pedagógicos, do processo de avaliação, bem como das concepções de educação e de sociedade.

Para Paulo Freire (1997), o ser humano é por natureza um ser inconcluso, constituindo o inacabamento um dado da consciência humana. Ao se referir ao homem que a escola deve hoje formar, o autor enfatiza sua natureza ontológica. Sendo assim, ensinar é uma relação que se 
estabelece entre seres, o que significa dizer que não existe docência sem discência.

O que importa é que os conhecimentos sistematizados sejam confrontados com as experiências socioculturais e a vida concreta dos alunos, como meio de aprendizagem e melhor solidez na assimilação dos conteúdos. Do ponto de vista didático, então, o ensino consiste na mediação de objetivos-conteúdos-métodos que assegurem o encontro formativo entre os alunos e as matérias escolares, que é o fator decisivo da aprendizagem.

A escola que se quer constitui uma proposta dentro do paradigma de inclusão, em que se ressignifica as práticas desenvolvidas no cotidiano da escola, como exigência da reorganização do trabalho escolar. A inclusão consiste em uma significativa mudança na postura do professor e propõe a construção de um novo perfil de escola que, a partir de então, objetiva contemplar e valorizar a singularidade de cada um dos sujeitos, trabalhando para uma visão de conjunto e parceria na busca da transposição do ideal para o real.

Com a inclusão, podemos visualizar novos horizontes nos níveis escolar e da práxis social. A lógica das relações é repensada, passando a horizontalidade a sobrepor-se à verticalidade. Rediscute-se o papel dos administradores, dos especialistas, dos corpos docente e discente, dos funcionários e pais. Todos tornam-se co-agentes da prática pedagógica e da vida escolar. São parceiros, vivendo em sincronia, coerentes com o momento histórico e com a realidade sociocultural.

A inclusão reitera, pois, diretrizes e práticas decorrentes da concepção de que a educação é um processo histórico e tem, como locus específico, o espaço escolar inserido no contexto social.

No contexto escolar, o planejamento constitui uma tarefa docente que inclui tanto a previsão das atividades didáticas, em termos da sua organização e coordenação em face dos objetivos propostos, quanto a sua revisão e adequação no decorrer do processo de ensino.

O planejamento passa a ser participativo e coletivo, significando o substrato teórico-metodológico que norteia toda a prática pedagógica, fortalecendo a interação entre escola, realidade social, teorias e práticas educacionais.

Os objetivos contemplam a construção do conhecimento pelos alunos, o que sabe e o que precisa saber, levando em consideração sua realidade socioeconômica-cultural. 
Na organização e seleção de conteúdos, metodologias e recursos, o trabalho individual e solitário do professor cede lugar ao trabalho em grupo. Busca-se coletivamente as soluções e alternativas pedagógicas, bem como a conjugação de recursos didáticos e de metodologias convencionais com recursos alternativos e metodologias inovadoras.

O professor assume-se como um mediador na construção do conhecimento e não mais como um mero transmissor de conteúdos estanques e desvinculados da realidade. Os alunos sentem-se mais motivados, participativos, exercitando o diálogo e a criatividade, atuando como co-autores de uma escola onde todos são cidadãos críticos e autônomos.

A avaliação faz-se em conjunto, levando em consideração o aluno real (e não o ideal), respeitando sua bagagem cultural, sua linguagem, suas condições de aprendizagem e seu ritmo próprio. É uma avaliação que se faz diagnóstica e processual.

Estar na caminhada rumo a uma educação inclusiva constitui, pois, o primeiro e decisivo passo rumo à transformação tão sonhada e tão necessária. Trata-se de um desafio de grande dimensão, mas de viabilidade plena e, por que não dizer, necessária. Os problemas são inúmeros; muitos deles, antigos e ainda sem solução. Precisamos criar novas formas para lidar com eles, pois sabemos que a modernidade não deu conta de resolvêlos. Enfrentar os velhos problemas com as velhas estratégias significa não sair do lugar, representa olhar o velho cenário com os mesmos óculos, significa trilhar um caminho conhecido com os mesmos sapatos, ou seja, representa apostar novamente no fracasso do empreendimento. Precisamos, sim, ressignificar o cotidiano escolar através da construção de novos diálogos, de cujo contexto ninguém esteja excluído, de onde emerja e se consolide o maior de todos os valores da atualidade: o reconhecimento e o respeito pela diversidade humana como base de uma sociedade mais justa e mais solidária.

\section{ABSTRACT}

Nowadays, understanding the meanings conferred on the problematic experienced by people present three different concepts in school discourse about diversity, three types of ideological formation which clearly depict human attitudes to difference: exclusion, integration and inclusion, identified respectively as the paradigms of isolation, visibility and accessibility since each of them involves a study of the pedagogical process. Three discursive formation systems, 
therefore, coexist within the pedagogical process, of education which 'denies' the existence of the other, that which houses and 'shapes' the other and finally, that which experiences the 'complexity' of/in the day-to-day in its diversity and richness.

Key words: education; difference; inclusion; pedagogical process.

\section{REFERENNCIAS}

ARROYO, M. Pedagogias em movimento: o que temos a aprender dos movimentos sociais? Belo Horizonte: UFMG, 2001. Mimeografado.

CANDAU, V. M. Multiculturalismo e direitos humanos. Disponível em: $<$ http:// www.dhnet.org.br/direitos/militantes/veracandau/Multicutaralismo.html\#3> Acesso em: 28 ago. 2003.

FONSECA, V. da. Educação especial. 2. ed. Porto Alegre: Artes Médicas, 1995.

FREIRE, P. Pedagogia da autonomia. 2. ed. São Paulo: Paz e Terra, 1997.

LUCKESI, C. C. Equivocos teóricos na prática educacional. Rio de Janeiro: ABT, 1983.

MARQUES, C. A. A imagem da alteridade na mídia. 2001. Tese (Doutorado em Comunicação e Cultura) - Centro de Filosofia e Ciências Humanas, Escola de Comunicação, Universidade Federal do Rio de Janeiro.

NICOLESCU, B. Ciência, sentido e evolução: a cosmologia de Jacob Boehme, acompanhado do tratado Seis pontos teosóficos de Jacob Boehme. São Paulo: Attar, 1995.

SKLIAR, C. Seis perguntas sobre a questão da inclusão ou de como acabar de uma vez por todas com as velhas - e novas - fronteiras em educação. Revista Pró-Posições, v. 12, n. 2-3 (35-36), p. 11-21, jul./nov. 2001.

A educação que se pergunta pelos outros: e se o outro não estivesse aqui? In: LOPES, A. C.; MACEDO, E. (Orgs.) Currículos: debates contemporâneos. São Paulo: Cortez, 2002. p. 196-215.

SILVA, T. T. da. A produção social da identidade e da diferença. In: (Org.). Identidade e diferença: a perspectiva dos estudos culturais. Petrópolis: Vozes, 2000.p. 73-102.

VAZ, P. O corpo-propriedade. s.n.t. Mimeografado. 